\title{
Multi-sensory experience design analysis on elderly toy products
}

\author{
YanMin Xue ${ }^{1}$, Rui Yan², XuYang Zhang ${ }^{3}$ \\ ${ }^{1}$ Design, Xi'an University of Technology, Xi'an, Shaanxi Province \\ ${ }^{2}$ Design, Xi'an University of Technology, Xi'an, Shaanxi Province \\ ${ }^{3}$ Industrial Design, Xi'an University of Technology, Xi'an, Shaanxi Province
}

\begin{abstract}
With the increasing needs of the people's good life in our country, the physical and psychological needs of the elderly have also received more and more attention from society. Toy products can fill the living needs and spiritual needs of the elderly to a certain extent. Therefore, this article will be from the perspective of multi-sensory design, Case studies of different categories of elderly toy products, exploring the differences and diversity of sensory designs in elderly toy products, in order to understand the important factors that need attention in the design of toy products for the elderly, upgrade the elements of the development of toy products for the elderly.
\end{abstract}

\section{Introduction}

Since the 21 st century, China has officially entered an aging society. According to the 2018 National Economic and Social Development Economic Bulletin, as of the end of 2018, the population over 65 years of age has reached 165.68 million, and the population aged 65 and over accounts for $8.9 \%$ of the total population[1]. The increase in the number of elderly people and the increase in quality of life requirements have opened up the market for elderly toy products. Older toys have similarities with ordinary toys and have different characteristics. The elderly have the characteristics of emotional loneliness and environmental exclusion loneliness in China[2]. Therefore, for elderly users, not only must they meet the basic design principles of elderly products, but they may pay attention to the multi-sensory experience of elderly users before, during and after use.

\section{Overview of toys products for the elderly}

Toys, as part of the fun source in the lives of the elderly, play a role in companionship, brain benefit and fitness. Toys can not only improve the hand-brain dissonance caused by the physical inconvenience of the elderly, but also improve the emotional communication and improve the autism and loneliness of the elderly in the process of participating in entertainment[3]. Therefore, the importance of toy products for the elderly is obvious.

\subsection{Development Status of Toy Products for the Elderly}

The common elderly toy products in China mainly include Taiji ball, Diabolo, Gyro, Turn walnut, Tangram, Luban lock, building blocks, Mahjong, etc. The above-mentioned toys for the elderly are more traditional in form and simple in function, and most of them are not specifically designed for the elderly, and it is difficult to meet the spiritual needs of the elderly. In recent years, there have been some desktop toys for the elderly in the market. Most of these toys are extended from existing children's and young people's toys, such as Rubik's cube, memory chess, big-character playing cards, and four-color games. Desktop entertainment project to achieve the purpose of training the elderly's perception and stimulate the elderly's joyful mood. Because many countries in foreign countries have entered the aging society early, there are many types and diverse forms of toys for the elderly in foreign countries. They are not limited to indoors and desktops. Outdoor toy products are also common, such as throwing toys such as frisbee golf and non-volleyball. There are also a variety of game forms, some of which can be completed by elderly users alone, or some of which can be achieved by cooperating with each other.

With the rapid development of science and technology, toy products for the elderly are mechanized and intelligent. For example, the companion pet robot Huggler designed and developed by Singapore for the elderly, and a stylish entertainment projection system for the elderly to perform various games conveniently and quickly[4], intelligent Toy products have played a role in promoting emotional communication among the elderly. It can be seen that, whether it is a traditional toy product for the elderly or an emerging toy product for the elderly, they stimulate the senses of the elderly at various stages of use through segments to create different experiences for the elderly when using the toy. 


\subsection{Classification of Toy Products for the Elderly}

According to the existing toy products for the elderly in the market, this article classifies toy products for the

Table 1. Classification of toys for the elderly

\begin{tabular}{lll}
\hline Toy purpose & Toys & Examples of toys \\
\hline Competitive & Throwing target toy & $\begin{array}{l}\text { Frisbee golf } \\
\text { Giant inflatable dice throw } \\
\text { Bowling, Velcro throw } \\
\text { Wooden ladybug guessing fist }\end{array}$ \\
& Guessing toys & Balance prickly pear \\
& Object balance toy & Balance moon \\
Cducational & Color matching \\
& Identifying matching toys & Shape matching \\
& Sorting toys & Huarong Road \\
& Space imagination toy & Building blocks \\
\hline Fitness class & Ball toys & Shoot balloon \\
& & gym ball \\
& Body balance toy & Spot walking \\
& & Chair pull rope \\
& Item delivery toy & Pass ring \\
& & Circular wave \\
\hline Smart class & Smart companion pet toy & Huggler \\
& Electronics toys & Stylish entertainment projection \\
& & system \\
\hline Multi-species & Use the product to interact with your pet & Pet obstacles moving forward \\
\hline
\end{tabular}

Although the above table is divided into five categories according to the main functions of elderly toy products, there are more than one function for elderly toy products. It can be seen that the classification of elderly toy products is not completely separated, but the main function drives auxiliary functions, and as far as possible, it is functionally suitable for most elderly users. The realization of the function is inseparable from sensory stimulation. Moderate sensory stimulation enables the elderly to perceive the good experience brought by toy products, which helps to improve the entertainment quality of the elderly and gradually develop a confident and optimistic attitude. Therefore, the differentiation and diversity of multi-sensory designs in toys for the elderly contribute to the development of products for the elderly.

\section{Elaboration of sensory functions}

Feeling is the simplest and most basic psychological process, and it plays an extremely important role in people's various activities. In addition to human beings' ability to distinguish the individual attributes of external things and understand the status of their own organs, all higher-level and more complex psychological activities, such as thinking, emotion, and will, are generated on the basis of feelings[5]. Multi-sensory in this article refers to vision recognized by eye perception, hearing sense identified by ear perception, smell sense identified by nose perception, taste perception identified by tongue perception, and skin perception identified by skin perception. When the elderly use toy products, these five organs interact and influence each other to form a complete experience process. elderly into competitive, intellectual, fitness, smart, and multi-species interaction categories based on the toy form. 
experience is an important factor in reducing adverse psychological effects.

\section{Comparative analysis of multi-sensory design in different types of toy products for the elderly}

Different types of toys for the elderly have different forms, different usage methods, and different senses for mobilizing user participation. The user experience formed by a single sensory participation is more monotonous, and the user experience formed by multiple sensory participations may leave a deep impression on the elderly users, help the elderly users to form different memories, and make the elderly users feel plentiful and maintain good life, mood.

\subsection{Sensory analysis of competitive elderly toys}

Competitive toy products mainly inspire the elderly's enthusiasm. Through fun and simple game regulars, they can compare with each other to get joy. Select the giant inflatable dice as an example to perform sensory analysis during the user's use process. The user obtains two face-up points by throwing two giant inflatable dice one by one as the single digit and the ten digits, respectively. The simple toy and number combination game mechanism stimulates the elderly to compare with each other and achieve the purpose of physical exercise during the throwing process.

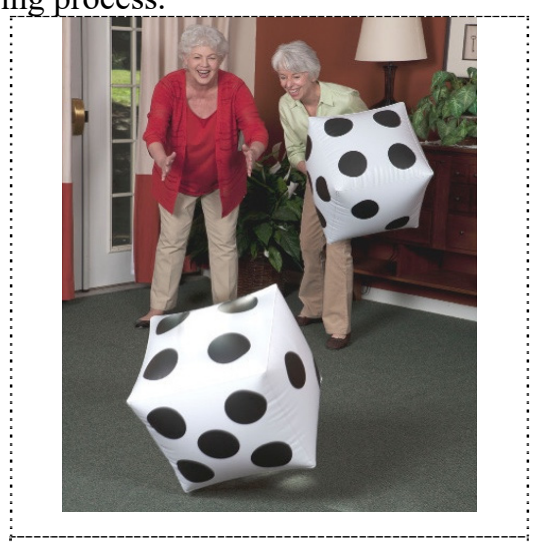

Figure 1. Giant inflatable dice.

Table 2. Sensory analysis when users use frisbee golf

\begin{tabular}{llllll}
\hline Giant inflatable dice & Vision & Hearing & Smell & Taste & Skin perception \\
\hline Before use & $\begin{array}{l}\text { Static, Rounded shape, } \\
\text { Simple colors }\end{array}$ & no & no & no & no \\
\hline Using & $\begin{array}{l}\text { Dynamic, scroll, } \\
\text { bounce, collision }\end{array}$ & Thumping & no & no & $\begin{array}{l}\text { Soft to the touch, } \\
\text { Suitable temperature }\end{array}$ \\
\hline After use & No change & no & no & no & no \\
\hline
\end{tabular}

According to the above case analysis, competitive elderly toys are mainly based on visual sensory experience, supplemented by auditory sensory experience, and these two factors are used to stimulate the elderly's competitive mentality.

\subsection{Sensory analysis of educational toys for the elderly}

Educational toys are mainly used to coordinate the hands, eyes, and brains of elderly users to achieve the purpose of games and benefit the brain. Taking balanced prickly pear as an example for sensory analysis during user use, balanced prickly pear is a toy that can be freely spliced and combined, but how to maintain balance on the basis of beauty is difficult, and it has trained the elderly's brain.

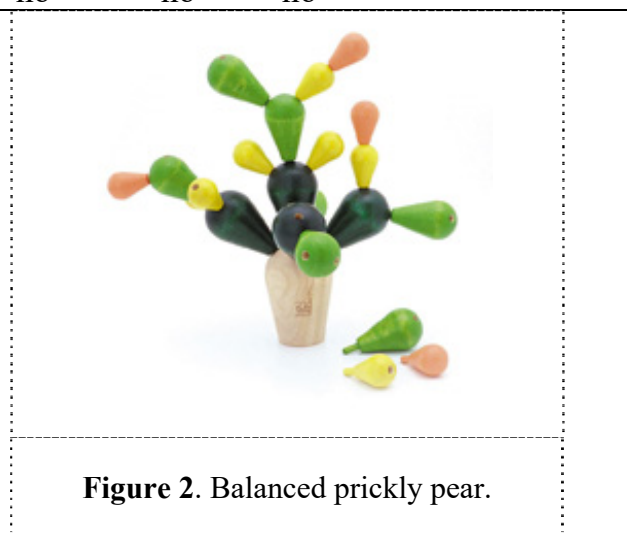

Table 3. Sensory analysis when users use Balanced prickly pear

\begin{tabular}{llllll}
\hline $\begin{array}{l}\text { Balanced } \\
\text { prickly pear }\end{array}$ & Vision & Hearing & Smell & Taste & Skin perception \\
\hline before use & $\begin{array}{l}\text { Static, Rounded shape, Multi } \\
\text {-module, Wooden, Rich colors }\end{array}$ & no & no & no & no \\
\hline Using & Modeling change, Color change & $\begin{array}{l}\text { Slight } \\
\text { collision }\end{array}$ & no & no & $\begin{array}{l}\text { Hard to touch, } \\
\text { Suitable temperature }\end{array}$ \\
\hline After use & $\begin{array}{l}\text { Static, Rounded shape, Appearance } \\
\text { change, Colorful }\end{array}$ & no & no & no & no \\
\hline
\end{tabular}

Through the above case analysis, educational toys for the elderly are mainly visual, which stimulates the 
thinking of the elderly, of which appearance is particularly important.

\subsection{Sensory analysis of fitness toys for the elderly}

Fitness toys mainly use the user's limb movements to achieve the purpose of the elderly to exercise muscles and bones. Select the circular wave as an example to perform sensory analysis during the user's use. The circular wave consists of a wavy hard iron wire and some perforated discs. Older users extend their arms so that the disc enters one end of the wire, and changes the angle of the wire to the horizontal The falling speed and direction of the disc will change, and the silver bell-like crisp sound of the discs colliding with each other will also be different, so as to achieve the purpose of training the upper limbs of the elderly.

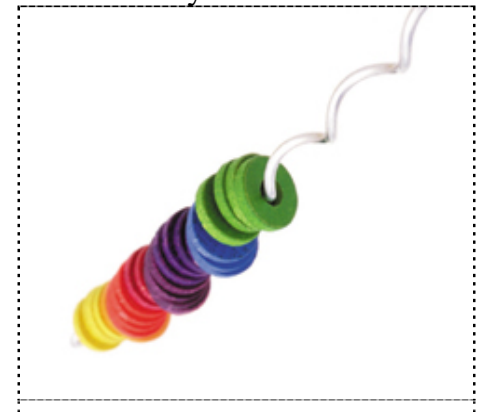

Figure 3. Circular waves.

Table 4. Sensory analysis when users use Circular waves

\begin{tabular}{llllll}
\hline $\begin{array}{l}\text { Circular } \\
\text { waves }\end{array}$ & Vision & Hearing & Smell & Taste & Skin perception \\
\hline Before use & $\begin{array}{l}\text { Static, Colorful, Slim } \\
\text { shape }\end{array}$ & no & no & no & no \\
\hline Using & Dynamic, Position change & $\begin{array}{l}\text { Changing slight } \\
\text { collision sound }\end{array}$ & no & no & $\begin{array}{l}\text { Hard to touch, } \\
\text { Suitable temperature }\end{array}$ \\
\hline After use & $\begin{array}{l}\text { Static, Color change, Part } \\
\text { position changes }\end{array}$ & no & no & no & no \\
\hline
\end{tabular}

Fitness toys for the elderly are mainly based on visual and auditory factors to promote the physical movement of the elderly.

\subsection{Sensory analysis of smart elderly toy products}

Intelligent toys combined with artificial intelligence, based on human-computer interaction, promote the elderly's communication activities, which is of some interest. Select the pet robot huggler as an example to perform sensory analysis during the user's use. When the

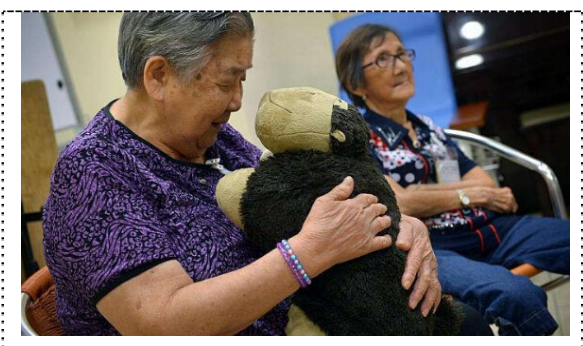

Figure 4. The pet robot huggler. user touches different positions of the huggler, they will make different sounds, such as giggling and snoring.

Table 5. Sensory analysis when users use the pet robot huggler

\begin{tabular}{llllll}
\hline Huggler & Vision & Hearing & Smell & Taste & Skin perception \\
\hline Before use & $\begin{array}{l}\text { Static, Rounded shape, Monkey } \\
\text { appearance }\end{array}$ & no & no & no & no \\
\hline Using & $\begin{array}{l}\text { Dynamic, Morphological } \\
\text { change }\end{array}$ & Voice response & no & no & Feel soft, Warmer \\
\hline
\end{tabular}

After use No change
hearing and touch as sensory note factors to help the elderly find fun.

\subsection{Sensory analysis of multi-species interactive elderly toy products}

Multi-species interactive toys. Participants include users, toys, and other living things. Not only human-machine or everyone-to-people communication. The addition of other living things makes the use of toys more interesting. Select the behavior example before pet obstacle for sensory analysis during user use. Many elderly users use giant cotton swabs to set obstacles for pets and guide the pet's direction. 


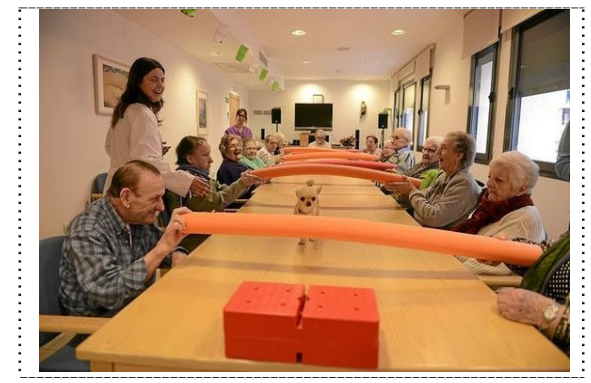

Figure 5. The pet robot huggler.

Table 6. Sensory analysis when users use Pet obstacles moving forward

\begin{tabular}{llllll}
\hline $\begin{array}{l}\text { Pet obstacles } \\
\text { moving forward }\end{array}$ & Vision & Hearing & Smell & Taste & $\begin{array}{l}\text { Skin } \\
\text { perception }\end{array}$ \\
\hline before use & $\begin{array}{l}\text { Static + dynamic, } \\
\text { Rounded, slim, Dog }\end{array}$ & Pet dog barking & no & no & no \\
\hline Using & $\begin{array}{l}\text { Dynamic, Pet dog } \\
\text { position change }\end{array}$ & $\begin{array}{l}\text { Cotton swab crash, } \\
\text { Pet dog barking }\end{array}$ & no & no & $\begin{array}{l}\text { Feel soft, } \\
\text { Warmer }\end{array}$ \\
\hline After use & No change & No change & no & no & no \\
\hline
\end{tabular}

The visual and sensory factors in multi-species interactive toys for the elderly use a combination of motion and static; the auditory sensory factors combine the sounds of nature and unexpected sound changes, bringing surprises and fun to the elderly.

\section{Conclusion}

The multi-sensory design in the toy products for the elderly has various designs, and different combinations can bring different experiences to the elderly users. Most senior toy products use both visual and auditory senses. In the factors of shape, color, sound, etc., the multi-sensory experience design between the toy and the user is designed. The tactile sensory experience almost meets the general guidelines for the design of elderly products. Generally, materials that are soft to the touch and suitable for the temperature will not cause pain. At present, in the market for the elderly toys and the cases analyzed above, smell and taste do not seem to be important sensory experience elements, but in life, the elderly also wants to get rid of the elderly taste. As part of the sensory experience, the entertainment experience for seniors may be more enjoyable.

\section{Acknowledgments}

This paper was supported by Chinese Ministry of education of Humanities and Social Science (project No. 17YJAZH100) and Humanities and Social Science Program of Shaanxi Province (Project No. 2018K13).

\section{References}

1. National Bureau of Statistics of the People's Republic of China. Statistical Communiqué of the National Economic and Social Development 2018 [R]. Beijing: National Bureau of Statistics of the People's Republic of China, 2018.

2. Tang Yan, Jin Guifang, Cang Shijian. Exploring toys design for the elderly from the perspective of lonely psychology of the elderly [J]. Art and Design (Theory), 2016, 2 (12): 114-116.

3. Ma Zhouyang. Research and application of design of elderly toys based on user experience [D]. Shaanxi University of Science and Technology, 2015.

4. Zhang Gong. Probe into the design direction and reference dimension of toys for the elderly [J]. Mechanical Engineering and Automation, 2018 (01): 222-224.

5. Product design and development. The third edition. 